\title{
Manual therapy in the treatment of patients with hemophilia B and inhibitor
}

Rubén Cuesta-Barriuso ${ }^{1,2,3^{*}}$ (D) and Roberto O. Trelles-Martínez ${ }^{4}$

\begin{abstract}
Background: The main clinical manifestations of hemophilia are muscle and joint bleeding. Recurrent bleeding leads to a degenerative process known as hemophilic arthropathy. The development of inhibitors (antibodies against FVIII/ FIX concentrates) is the main complication in the treatment of hemophilia. The objective was to assess the safety and efficacy of manual therapy treatment in a patient with hemophilia and inhibitor.

Case presentation: A 26-year-old patient with hemophilia B and inhibitor received physiotherapy treatment based on manual therapy for 3 months, with a frequency of 2 sessions per week. The joint status was evaluated using the Hemophilia Joint Health Score; pain was assessed with the Visual Analog Scale; and the range of movement was evaluated using a universal goniometer. The patient developed no joint bleeding in the knees or ankles as a result of the physiotherapy treatment. Following treatment, improvements were noted in the range of movement of knees and ankles, the perception of pain in both knees, and ankle functionality.

Conclusions: Until now, manual therapy using joint traction was contraindicated in patients with hemophilia and inhibitor, as it was feared to cause possible joint bleeding. This is the first case study to address the safety and efficacy of manual therapy in a patient with hemophilia and an inhibitor. The results of this study may help to establish which manual therapy treatments are indicated in patients with hemophilic arthropathy and inhibitors. Thus, a physiotherapy program based on manual therapy may be safe in patients with hemophilia and inhibitor and such therapy may improve joint condition, pain, and joint range of motion in patients with hemophilia and inhibitor. Randomized clinical trials are needed to confirm the results of this case study.
\end{abstract}

Keywords: Hemophilia inhibitor, Joint damage, Physiotherapy, Case report, Hemophilia arthropathy, Inhibitor, Manual therapy, Hemophilic arthropathy, Safety

\section{Background}

Hemophilia is a congenital coagulopathy characterized by the absence of certain clotting factors: factor VIII (Hemophilia A) or factor IX (hemophilia B). Pharmacological treatment involves the intravenous administration of concentrates of the missing clotting factor, either periodically (prophylactic treatment) or in the event of bleeding (on demand) [1].

The development of inhibitors (antibodies) against the exogenous factor administered is the main complication in the treatment of hemophilia. The prevalence of inhibitors is higher in hemophilia A than in hemophilia B. The reported prevalence of inhibitors in unselected

\footnotetext{
* Correspondence: ruben.cuestab@gmail.com

${ }^{1}$ Department of Physiotherapy, European University of Madrid, Madrid, Spain

${ }^{2}$ Royal Victoria Eugenia Foundation, Madrid, Spain

Full list of author information is available at the end of the article
}

haemophilia populations is generally reported to be about $5-7 \%$ [2]. These patients present a higher bleeding phenotype, with the added complication of the pharmacological approach needed to control the hemorrhagic process. For this reason, degenerative joint lesions are more common in patients with hemophilia and inhibitors than in those without antibodies against the clotting factor [3].

The deficient production of one of these clotting factors entails, rather than an increase in bleeding, an alteration in the control thereof. Healthy subjects experience bleeding (microhemorrhages) on a daily basis, which their coagulation system controls immediately, so the events go unnoticed. However, in patients with hemophilia these microbleedings are not controlled, triggering muscle and joint bleeding and thus the hemorrhagic clinical pattern characteristic of this disease. In particular, hemophilia is 
characterized by the development of hemorrhages in the locomotive apparatus, especially in the knee, ankle and elbow joints [4]. Repeated hemorrhagic episodes in the same joint, in the long term lead to the emergence of a progressive joint degeneration known as hemophilic arthropathy [5]. This arthropathy presents, among other symptoms, with chronic pain, decreased joint range of motion and muscle strength, and proprioceptive and gait disorder, when it affects lower limbs [6].

The literature reveals many studies that have assessed the safety and efficacy of different physiotherapy techniques in the approach to the hemophiliac patient $[7,8]$. However, one of the most widespread exclusion criteria in most studies on hemophilia is the development of inhibitors. The risk of bleeding, the complexity of hemostatic management and control and the uncertainty in the process of evaluating the safety of a technique, are three of the main reasons for the non-inclusion of patients with inhibitors.

This paper describes a case study to evaluate the safety of a manual physiotherapy intervention in a patient with hemophilia B and inhibitors.

\section{Case presentation}

The patient is 26 years-old, $179 \mathrm{~cm}$ in height and weighs $67 \mathrm{~kg}$. At the time of the study the patient was working (active work, eight hours a day), he had a medical diagnosis of bilateral hemophilic arthropathy in knees, ankles and elbows, and was administered daily $60 \mathrm{mg}$ Etoricoxib (selective COX-2 inhibitor) and $150 \mathrm{mg}$ Tramadol (opioid), for pain control. The patient reports to have had moderate-severe pain for more than 3 years, requiring painkillers on a daily basis for 3 years. In the 6 months prior to the study he developed 6 hemarthrosis in the lower limbs (1 in the right knee, 1 in the left knee, and 4 in the left ankle). The patient is on the waiting list to undergo orthopedic surgery for total right knee replacement. In the months prior to the study, he underwent two radiosynovitis interventions (in his right elbow and left ankle joints). His clinical and functional situation is currently affecting his work performance, with a moderate amount of time away from work. The pharmacological treatment received is based on a prophylaxis regime (5 IU of Novoseven, every $48 \mathrm{~h}$ ). Figure 1 shows the lower limbs and their radiological image (Fig. 1).

A manual orthopedic therapy intervention has been carried out by means of range I-II joint traction in knees and ankles [9], for a period of 3 months, with a frequency of two weekly 45-min sessions. In each session, submaximal mobility traction of knees and ankles $(80 \%$ of the range of motion) was carried out, with the aim of reducing pain and improving knee and ankle mobility. The treatment involved $15 \mathrm{~min}$ of joint traction in ankles and another $15 \mathrm{~min}$ in knees (grade I-II). The distal tibia and fibula were fixation with straps and the proximal talus was held in place manually with the patient in supine position and the traction was carried out in the submaximal ranges of dorsal and plantar flexion to traction the ankle. Figure 2 shows the joint traction technique of the ankle. For knee joint traction, we placed the patient in the prone position, performing traction (grade I-II) in submaximal flexion and knee extension, using a strap and manually securing the distal part of the femur. Traction was maintained for $15 \mathrm{~s}$, with a 20-s interval between each joint traction [9].

Before and after the intervention three dependent variables were evaluated: range of motion, pain and joint condition. Range of motion of dorsal and plantar ankle flexion and flexion and knee extension were measured
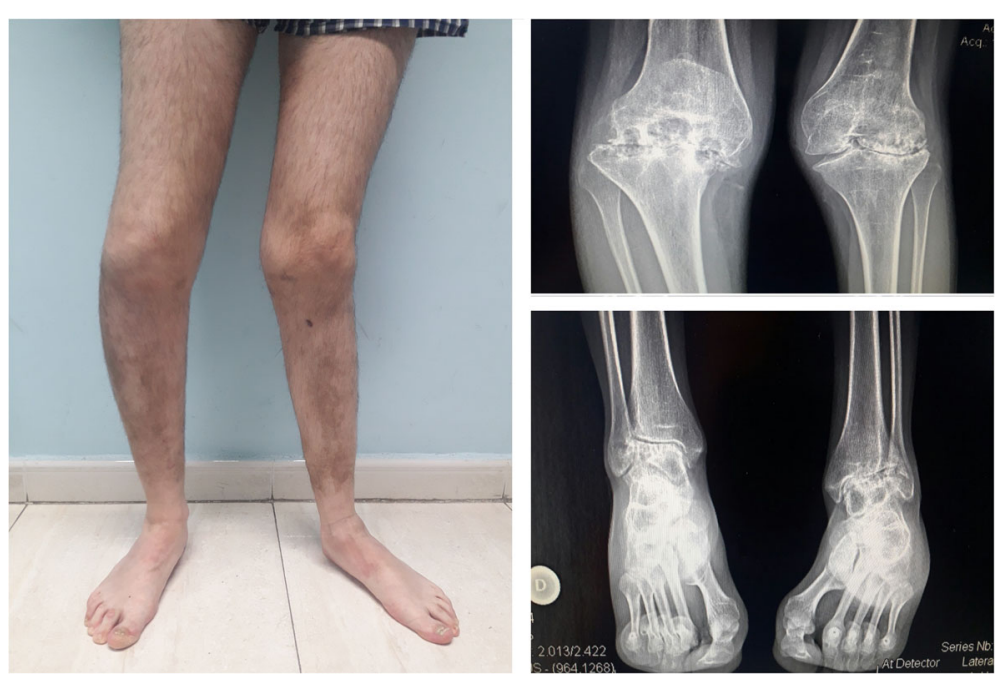

Fig. 1 Shows an image of the patient's lower load-bearing limbs 


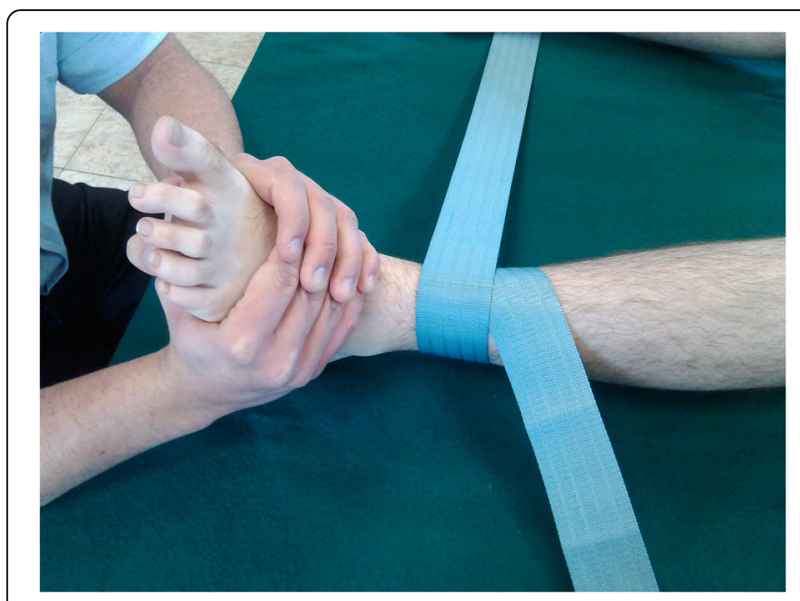

Fig. 2 Shows a traction joint of ankle

using a universal goniometer. The anatomical references used were those identified by Querol [10], using the zero-reference method for the mobile arm of the goniometer, as described by Norkin et al. [11]. Pain perception was measured using the visual analog scale, VAS, with scores ranging from 0 to 10 points (from no pain, to the maximum pain imaginable). Joint condition was evaluated using the Hemophilia Joint Health Score [12]. This scale consists of 8 items per joint (plus Gait being analyzed globally), evaluating joint swelling, duration of swelling, muscle atrophy, strength, crepitus on motion, flexion and extension loss, and pain. The total scores of the updated version of HJHS range from 0 to 124 points (0-20 points for each of the six joints evaluated, plus 4 points for the overall assessment of gait). At baseline, patient was given a self-record of bleeding and a telephonic follow-up was carried out over the $48 \mathrm{~h}$ following each treatment session. In this way, intervention safety was assessed, in terms of the occurrence of muscle and joint bleeding in the treatment area.

In addition to the physiotherapy treatment using manual therapy, no further intervention was performed. Moreover, the patient continued with his normal everyday activities throughout the treatment period. Upon completion of the treatment period improvement was noted in almost all ranges of knee and ankle movement. Moreover, improvement was noted in the perception of pain in both knees, and in ankle functionality. However, the main finding of this case study is the absence of hemorrhagic episodes in knees or ankles as a result of the intervention. Table 1 shows the results of dependent variables in both evaluations.

\section{Discussion and conclusions}

Physiotherapy in general, and manual therapy in particular, are two therapeutic tools recently introduced in the physiotherapy approach to patients with hemophilia, based on scientific evidence. However, there are no studies including patients with inhibitors which would enable verification of the safety of these techniques in this group of patients.

This is the first case study to conduct a physiotherapy intervention using joint traction to assess the safety of manual therapy in hemophiliacs with inhibitors. During the treatment period, the patient with hemophilia and

Table 1 Main statistical data of the evaluations carried out in the present case study

\begin{tabular}{|c|c|c|c|c|}
\hline \multirow[t]{2}{*}{ Variables } & \multirow[t]{2}{*}{ Measurement } & \multicolumn{2}{|c|}{ Assessment } & \multirow{2}{*}{$\begin{array}{l}\text { Percentage of } \\
\text { improvement }\end{array}$} \\
\hline & & Baseline & Posttreatment & \\
\hline \multirow{8}{*}{$\begin{array}{l}\text { Range of motion } \\
\text { (degrees) }\end{array}$} & Flexion right knee (degree) & 75 & 75 & 0.00 \\
\hline & Flexion left knee & 100 & 117 & 17.0 \\
\hline & Extension right knee & -18 & -17 & 5.50 \\
\hline & Extension left knee & -16 & -6 & 62.5 \\
\hline & Dorsal flexion right ankle & 2 & 3 & 50.0 \\
\hline & Dorsal flexion left ankle & -2 & -2 & 0.00 \\
\hline & Plantar flexion right ankle & 29 & 38 & 62.1 \\
\hline & Plantar flexion left ankle & 26 & 29 & 11.5 \\
\hline \multirow{4}{*}{$\begin{array}{l}\text { Joint pain } \\
\text { (0-10 points) }\end{array}$} & Right knee & 5 & 4 & 20.0 \\
\hline & Left knee & 3 & 2 & 33.3 \\
\hline & Right ankle & 0 & 0 & 0.00 \\
\hline & Left ankle & 2 & 1 & 50.0 \\
\hline \multirow{4}{*}{$\begin{array}{l}\text { Joint status } \\
\text { (0-20 points) }\end{array}$} & Right knee & 11 & 11 & 0.00 \\
\hline & Left knee & 10 & 10 & 0.00 \\
\hline & Right ankle & 10 & 8 & 20.0 \\
\hline & Left ankle & 9 & 8 & 11.1 \\
\hline
\end{tabular}


inhibitors suffered no joint or muscle hemorrhages in knees or ankles. Although the patient developed haemarthrosis in the knees, this was caused by trauma, clearly located by the subject at the onset of clinical symptoms. Therefore, it may be concluded that in hemophiliacs with inhibitors, Grade I-II joint traction in knees and ankles appears to be safe, provided it is performed within a range of submaximal mobility and assisted by a manual therapy specialist.

Range of motion improvement noted in knees and ankles is consistent with that observed in other similar studies $[9,13]$ implementing manual therapy. The results which differ based on the knee or ankle assessed, depend on the clinical condition of the joint. Axial deformities, osteophytosis and the narrowing of the articular space, are three clinical factors that especially limit expectations. Therefore, an approach based on the joints (joint capsule), muscles and fascia, is essential in range of motion improvement.

Chronic pain is one of the most limiting and disabling clinical manifestations in patients with hemophilia [14]. Chronic pain is characteristic of hemophilic arthropathy and has been described as the main cause of disability in these patients, affecting their functional capacity and quality of life [15]. The improvement achieved in the knees, reported by the patient to be the joints with most pain at pretreatment assessment, is substantial. Decompression of the joint space, in addition to elongation of the articular capsule, can relieve pain in patients with hemophilia and inhibitors and significant joint deterioration. To this end, it is vital to develop the technique, strictly following manual therapy criteria and methodology, in order to avoid bleeding episodes.

This study aims to achieve the inclusion of patients with inhibitors in clinical studies using physiotherapy in hemophilia. These patients, who normally suffer more disabling joint symptoms than subjects without inhibitors, need a specialized and evidence-based approach. Establishing well-designed physiotherapy protocols implemented by hemophilia specialists may be the first step in the development of scientific evidence, unavailable to date $[16,17]$.

Coordination between the various specialists who treat patients with hemophilia (hematologists, nurses, orthopedic surgeons, physiotherapists, etc.) is essential for a proper approach [18].

For patients with inhibitors, whose frequency of bleeding is higher and who reach adulthood in more disabling musculoskeletal conditions, coordination of the interventions among the entire healthcare team is critical. As a step prior to orthopedic surgery, the combined effort of hematologists and physiotherapists is essential to delay surgery as much as possible, maintaining the patient's functionality and perception of quality of life [19].

\section{Abbreviations}

COX: Cyclooxygenase

\section{Acknowledgements}

Not applicable.

\section{Funding}

The authors state that this work has not received financial support.

\section{Availability of data and materials}

All data generated or analyzed during this study are included in this published article.

\section{Authors' contributions}

RCB treated the patient and designed the study. RCB and RTM collected and analyzed the data and wrote the article. All authors have read and approved the manuscript.

\section{Ethics approval and consent to participate}

This study was approved by the Ethics Committee of the University of Murcia (registration number 43/2011).

\section{Consent for publication}

This manuscript has the consent of the patient for the use of his data and image of lower limbs. The authors obtained the written consent of the patient for the publication of the data and images that appear in the article.

\section{Competing interests}

The authors declare that they have no competing interests.

\section{Publisher's Note}

Springer Nature remains neutral with regard to jurisdictional claims in published maps and institutional affiliations.

\section{Author details}

'Department of Physiotherapy, European University of Madrid, Madrid, Spain. ${ }^{2}$ Royal Victoria Eugenia Foundation, Madrid, Spain. ${ }^{3}$ Fishemo SLU-Spanish Federation of Hemophilia, Madrid, Spain. ${ }^{4}$ Department of Hematology, Clínico San Carlos Hospital Madrid, Madrid, Spain.

Received: 4 September 2017 Accepted: 10 January 2018

Published online: 22 January 2018

References

1. Manco-Johnson MJ, Abshire TC, Shapiro AD, Riske B, Hacker MR, Kilcoyne R, et al. Prophylaxis versus episodic treatment to prevent joint disease in boys with severe hemophilia. N Engl J Med. 2007;357:535-44.

2. Hay CR. The epidemiology of factor VIII inhibitors. Haemophilia. 2006;12(6):23-8.

3. Morfini M. Articular status of haemophilia patients with inhibitors. Haemophilia. 2008;14(Suppl. 6):20-2.

4. Goddard NJ, Mann H. Diagnosis of haemophilic synovitis. Haemophilia. 2007;13(3):14-9.

5. Valentino LA, Hakobyan N, Enockson C. Blood-induced joint disease: the confluence of dysregulated oncogenes, inflammatory signals and angiogenic cues. Semin Hematol. 2008:45:50-7.

6. Stephensen D, Tait RC, Brodie N, Collins P, Cheal R, Keeling D, et al. Changing patterns of bleeding in patients with severe haemophilia a. Haemophilia. 2009; 15(6):1210-4.

7. Goto M, Takedani H, Haga N, Kubota M, Ishiyama M, Ito S, et al. Selfmonitoring has potential for home exercise programmes in patients with haemophilia. Haemophilia. 2014;20:e121-7.

8. Runkel B, Von Mackensen S, Hilberg T. RCT-subjective physical performance and quality of life after a 6-month programmed sports therapy (PST) in patients with haemophilia. Haemophilia. 2017;23:144-51.

9. Cuesta-Barriuso R, Gómez-Conesa A, López-Pina JA. Effectiveness of two modalities of physiotherapy in the treatment of haemophilic arthropathy of the ankle: a randomized pilot study. Haemophilia. 2014;20:e71-e78.

10. Querol F. Exploración clínica de la artropatía hemofílica. Palmero ediciones: Valencia; 2008.

11. Norkin C, White J. Goniometría. Marban: Evaluación de la movilidad articular Madrid; 2006. 
12. Feldman BM, Funk SM, Bergstrom BM, et al. Validation of a new pediatric joint scoring system from the international hemophilia prophylaxis study group: validity of the hemophilia joint health score. Arthritis Care Res. 2011; 63(2):223-30.

13. Cuesta-Barriuso R, Gómez-Conesa A, López-Pina JA. Manual therapy in the treatment of ankle hemophilic arthropathy. A randomized pilot study. Physiother Theory Pract. 2014;30(8):534-9.

14. Stephensen D, Rodriguez-Merchan EC. Orthopaedic co-morbidities in the elderly haemophilia population: a review. Haemophilia. 2013;19:166-73.

15. Santavirta N, Solovieva S, Helkama O, Lehto S, Konttinen YT, Santavirta S. Musculoskeletal pain and functional ability in haemophilia a and B. Physiotherapy and rehabilitation in haemophilia patients. Rheumatol Int. 2001;21:15-9.

16. Schafer GS, Valderramas S, Gomes AR, Budib MB, Wolff ALP, Ramos ATT. Physical exercise, pain and musculoskeletal function in patients with haemophilia: a systematic review. Haemophilia. 2016;22:e119-e129.

17. Cuesta-Barriuso R, Gómez-Conesa A, López-Pina JA. Physiotherapy treatment in patients with hemophilia and chronic ankle arthropathy: a systematic review. Rehabil Res Pract. 2013;2013(305249)

18. Auerswald G, Dolan G, Duffy A, Hermans $C$, Jiménez-Yuste V, Ljung R, et al. Pain and pain management in haemophilia. Blood Coagul Fibrinolysis. 2016; 27:845-54.

19. Caviglia H, Narayan P, Forsyth A, Giangrande P, Gilbert M, Goddard N, et al. Musculoskeletal problems in persons with inhibitors: how do we treat? Haemophilia. 2012;18:54-60.

\section{Submit your next manuscript to BioMed Central} and we will help you at every step:

- We accept pre-submission inquiries

- Our selector tool helps you to find the most relevant journal

- We provide round the clock customer support

- Convenient online submission

- Thorough peer review

- Inclusion in PubMed and all major indexing services

- Maximum visibility for your research

Submit your manuscript at www.biomedcentral.com/submit 